\title{
Percentage of Cesarean Sections to Total Surgical Procedures: AnIndex Already Described
}

\author{
Paul Fenton
}

Published online: 7 February 2013

(c) Société Internationale de Chirurgie 2013

To the Editor,

I am writing to draw your attention to the following article in the World Journal of Surgery by Kushner et al. [1], which presents an indicator of surgical output that I described in an article published in June 1997 in the East and Central African Journal of Surgery titled: The Epidemiology of District Surgery in Malawi: A Two Year Study of Surgical Rates and Indices in Rural Africa. That publication was based on a study I carried out almost 20 years ago from 1993 to 1995, visiting 18 district hospitals every 3 months to collect data at considerable effort and personal expense.

Among several indices then cited as being of interest, I proposed the ratio "C/section: major operations" (CS:Maj) as an index useful in assessing the surgical performance of a particular hospital without having to count all the operations carried out there.

During that period in the 1990s there was almost zero interest in surgical practice in Africa among commentators and publications in international health, so the article received little comment. I also presented the same data at the 1st All Africa Anaesthesia Congress in Harare in 1997.

Now consultant to Gradian Health Systems LLC and inventor of the Universal Anaesthesia Machine.

P. Fenton

Department of Anaesthesia, College of Medicine,

Malawi 1986-2001, Malawi

Present Address:

P. Fenton $(\bowtie)$

Gradian Health Systems LLC, 160 Fifth Avenue,

7th Floor, New York, NY 10010, USA

e-mail: uam.paul@gmail.com
Recently, as the Millennium Development Goals approach their target dates, there has been a resurgence of interest in surgery. Newer authors have appeared, such as Kushner et al., many of them based in North America. Nongovernmental organizations campaigning for increased surgery in poorer countries abound, even though, like the established leader in the field (the World Health Organisation), it remains to be seen what actual benefit will result from their expenditure of time and money.

Because the 1997 print edition of the African journal is no longer available, the editor, Dr. Ignatius Kakande, kindly republished my article in 2011, and it is available online [2].

I corresponded with Dr. Kushner, the lead author, on surgical matters in 2009 and sent him my article one year before his study appeared in the World Journal of Surgery. However, there is no acknowledgement of, or reference to, my earlier publication, despite a responding email from Dr. Kushner in 2009 saying that he had received and read my 1997 article.

I think a formal acknowledgement by your journal that the Cs:maj index was previously described and published would be an appropriate step toward recognizing my original and pioneering work in this field.

\section{References}

1. Kushner AL, Groen RS, Kingham TP (2010) Percentage of cesarean sections to total surgical procedures in sub-Saharan Africa: a possible indicator for overall adequacy of surgical care. World J Surg 34:2007-2008

2. Fenton PM (2011) The epidemiology of district surgery in Malawi: a two year study of surgical rates and indices in rural Africa. East Central Afr J Surg 16:35-44. Available at http://www.bioline. org.br/abstract?id=js11048\&lang=en. Accessed 22/11/2012 